\title{
Assessing the Impact of the European Fiscal Compact on Eurozone Mediterranean States (With A Focus on Malta)
}

\author{
Dr Philip von Brockdorff \\ Prof Joseph Falzon
}

University of Malta

\section{Doi:10.5901/mjss.2014.v5n14p11}

\begin{abstract}
The paper assesses the impact of the European Fiscal Compact on Eurozone Mediterranean States with a focus on Malta by estimating deviations between potential and actual GDP for the Maltese economy, comparing the cyclical components of public revenues and expenditure, and estimating the cyclically adjusted deficit in excess of the requirement of 0.5 per cent structural deficit. A discussion on the structural nature of Malta's budget deficit ensues. Finally, by comparing public debt ratios of the selected States, the paper examines the policy implications of reducing the budget deficit for the Maltese Islands.
\end{abstract}

Keywords: Fiscal Compact; budget deficit; potential output; actual GDP; cyclical components of public revenue and expenditure; structural deficit; public debt.

\section{The Fiscal Compact: The Objectives}

The European Fiscal Compact is part of the Treaty on Stability, Cooperation and Governance in the Economic and Monetary Union. It binds all EU countries except for the UK and Czech Republic. The need for strong fiscal discipline is highlighted by the Treaty which in the event of default by subscribing Member States will result in automatic penalties. In other words, enforcement of fiscal discipline has become the order of the day. In fact, the Treaty puts the onus on Members States to balance their budget or aim for budget surplus. Thus, the annual structural deficit should not exceed 0.5 per cent of GDP. To achieve this, Member States will be required to introduce a target for a balanced budget and this will be enshrined in the Constitution of subscribing Member States. This implies that Member States will be liable to legal action by the European Commission in the event that this target is not reached. The deadline for this legal requirement is one year after the entry into force of the Treaty. In the event that the public debt is well below the 60 per cent mark and the Commission deems that the long-term sustainability risks of public finances in a Member State are low, then the structural deficit may reach up to 1 per cent of GDP.

\section{Will the Fiscal Compact Suffice for A Smooth Functioning of the Monetary Union?}

The legal requirements of a 3 per cent of GDP budget deficit ceiling and the 60 per cent of GDP ceiling for public debt have existed since 1992 in line with the Maastricht Treaty. Despite this, almost all Members States have registered budget deficits and public debts well beyond the 3 and 60 per cent mark. Again, despite the Stability and Growth Pact signed in 1997, aimed at bringing medium-term structural budget balance close to balance or surplus, this too was largely ignored. The fact that no enforcement measure was adopted may have been the cause for this continued flouting of rules by most Member States but there was no real commitment to fulfill the obligations as set out in the Maastricht Treaty and in the Stability and Growth Pact.

The new fiscal pact aims to address this by triggering an automatic correction mechanism and penalties in the event that a Member States is adjudged to have exceeded the limits. This may seem as the last course of action to take for a Eurozone or currency union which shares a monetary policy but not a fiscal union. When one considers that history has shown that successful monetary unions have happened when monetary union has been combined with fiscal union (as has been the case in the United States, Canada, Germany and Switzerland) agreement on a European Fiscal Compact appeared inevitable.

In fact, Bordo, Markiewicz, and Jonung (2011) claim that, in order to be successful, a monetary union needs an independent central bank with price stability as one of its main objectives; it also needs free trade movement of capital 
and production factors. In their opinion a common fiscal policy is also necessary, with effective fiscal rules in consonance with developments in the financial markets, where bail-out is no longer an option. Bordo et al also argue that there needs to be a robust set of instruments to address asymetric shocks when required such as automatic stabilizers; transferring financial resources to Member States affected by asymetric shocks; and the use of progressive income taxation.

However, the EU budget, which currently amounts to just above 1 per cent of the EU's GDP, is too low to be used as an instrument to address asymetric shocks, and as expected, fiscal transfers between Member States cannot take place even in times of asymetric shocks. It should also be noted that labour mobility is much lower in the EU than in the US. One reason for this is that labour laws are far more inflexible in the EU and this has made mobility across the EU more difficult and costly for both employers and employees. It is not surprising, therefore, that economies within the Eurozone have varying levels of competitiveness and economic development.

If we take industrial competitiveness alone, we find different levels of labour productivity across EU Member States, which can be grouped into three categories. The group of countries with a productivity rate considerably above the EU average includes Ireland, the Netherlands, Austria, Finland, Belgium, Luxembourg, Sweden and Germany. The second group of countries with a rate slightly above and below the EU average includes the United Kingdom, France, Denmark, Spain, Greece, Italy and Malta, whereas the third group of countries with a productivity rate considerably below the EU average includes Slovakia, Slovenia, Hungary, the Czech Republic, Poland, Cyprus, Portugal, Estonia, Lithuania, Romania, Latvia and Bulgaria.

Figure 1: Labour productivity per person employed in manufacturing

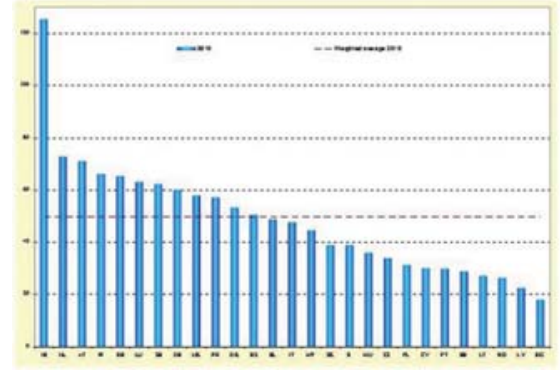

\section{Source: Eurostat}

The data on the share of innovating companies among Member States is also interesting. Countries can be classified into three groups. Those with a share exceeding 60 per cent include Germany and Luxembourg. The second group of countries with a share exceeding 50 per cent includes Belgium, Portugal, Ireland, Estonia, Austria, Cyprus, the Czech Republic, Greece, Sweden, Italy, Finland, Denmark, Slovenia and France; and a third group with a share exceeding 30 per cent includes the United Kingdom, the Netherlands, Spain, Malta, Slovakia, Romania, Bulgaria and Lithuania. The group of Member States with a share lower than 30 per cent includes Hungary, Poland and Latvia.

Figure 2: Share of innovating companies among all companies in percentage terms

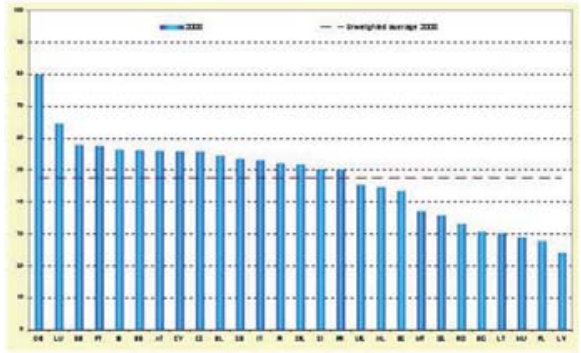

Source: Community innovation surveys 
Another indicator of varying levels of competitiveness across Member States is enterprises which have introduced new or significantly improved goods, services and/or processes, as well as marketing or organisational innovation during an observation period of three years. Figure 2 illustrates the share of those innovating companies in relation to the total number of enterprises. Contrasting levels of innovation range from Germany to Latvia. Malta does not score favourably in this survey. This should preoccupy the minds of policy makers, particularly if the objective of enlarging Malta's potential GDP is to be attained.

In terms of business friendliness of bureacracy, a survey among businesses (World Economic Forum) found that the group of Member States where regulation was less burdensome for companies (with a rating higher than 3.5) includes Finland, Estonia, Denmark, Cyprus, Sweden and Luxembourg. The group of Member States where it is more burdensome for companies (rating between 3.5 and 2.5 ) includes the Netherlands, Austria, Ireland, Latvia, Bulgaria, the United Kingdom, Germany, Slovenia, Spain, Lithuania, Malta, Romania, Slovakia, the Czech Republic, France and Poland. On the other hand, the group of Member States where the regulation was assessed as most burdensome (rating below 2.5) includes Belgium, Portugal, Greece, Hungary and Italy. Again, this shows varying degrees of competitiveness with Mediterranean Member States not ranking favourably.

Figure 3: Business-friendliness of government regulation

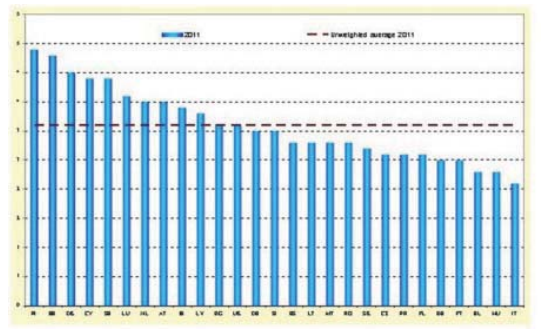

\section{Source: World Economic Forum survey}

Results (see Figure 3) were derived from a World Economic Forum survey among business executives which assessed how burdensome it is for businesses in the respective countries to comply with governmental administrative requirements such as permits, regulations or reporting requirements. The lower the values, the more burdensome the regulatory framework was assessed in the survey ( 1 = extremely burdensome; 7 = not burdensome at all).

It should be noted that these results were derived at a time when practically all Member States (including those hit hardest by the financial and economic crisis) were taking measures to reduce the administrative burden and were also and introducing measures (including fiscal ones) in order to encourage privately held companies to invest. Indeed, private sector investment is critical if economies across the EU are to grow beyond current levels of output, and provide muchneeded sources of fiscal revenues to address both cyclical and structural deficits.

\section{The Fiscal Compact and Its Implications for Malta}

In the first instance, one needs to draw a distinction between cyclical and structural deficit. Malta's actual budget is made up of these two components. The economic cycle impacts on both fiscal revenues and expenditures and these components serve to reduce GDP volatility. Furthermore, with a progressive tax system in place as is the case in Malta, the adjustment tends to be more effective. Nonetheless, the 'output-gap' (defined as the difference between actual and potential output) as well as the responsiveness of revenue and expenditure to a slowdown in economic activity adversely affects the cyclical deficit.

The structural deficit, on the other hand, is caused by factors arising independently from the economic cycle. Put differently, this component of the deficit still persists when the economy is midway between an economic boom and a recession. A structural deficit, therefore, can still occur when the economy is operating at its full potential. This is the opposite of a cyclical deficit which only occurs when an economy is not performing at its full potential (for example, if an economy is currently struggling through a recession). In the case of a cyclical deficit, loans required during the low point of the economic cycle will be repaid when the economy recovers and a cyclical surplus is recorded. In contrast, a structural deficit implies that a deficit will be posted regardless of how well the economy is functioning: recession, boom or 
anything in between. Failure to address this component of the deficit will seriously limit the effectiveness of revenues and expenditure in reducing GDP volatility.

A negative output gap occurs when actual output is less than potential output. This is also called a deflationary (or recessionary) gap. In this situation the economy is producing less than its potential. Low growth and /or a fall in output will result in higher unemployment levels. A negative output gap will also typically cause low inflation or even deflation. Factor resources such as labour and capital may be under-utilised resulting in further increases in unemployment, as has been the case in Greece, Spain, Italy and Cyprus where millions of people have had to contend with wage freezes or actual wage cuts at a time when businesses have been under huge pressure to cut their costs (and governments having to reduce spending and sovereign debt).

A positive output gap occurs when actual output is greater than potential output. This is the case when economic growth is above the long run trend rate, that is during an economic boom. With a positive output gap, there will be inflationary pressures. It will also tend to cause a bigger current account deficit as consumers buy more imports due to domestic supply constraints.

\section{Deviations between Potential and Actual GDP for the Maltese Islands}

In the section an estimation of the potential and the actual output is attempted. This is based on the Production Function method, and the deviations between potential and actual output at 2005 prices are based on European Commission estimates. The countries selected are Malta, Cyprus, France, Greece, Italy and Spain, which are all Mediterranean Member States and members of the Eurozone. The Production Function method is based on the relationship between inputs and output (goods and services combined). The method models potential output as a function of potential labour and capital inputs, as well as of potential total factor productivity (TFP). Therefore, the output gap measures how far the economy is from its full employment or the potential level that depends on supply-side factors of the economy: the supply of labour and capital and their productivity.

Of course, methods aimed at estimating potential output depend on numerous assumptions that are subject to uncertainty and error. It also relies on a simplistic representation of the production technology which omits the direct information regarding the related supply-side factors such as capacity utilisation, technology adoption, regulation, and human capital accumulation. However, the method allows fairly reasonable comparisons to be made between selected countries.

The output gap is expressed as a ratio of potential GDP and is indicative of the cyclical developments that have taken place in the Maltese economy. The gap between actual and potential GDP at 2005 prices was highest in 2004 but the potential GDP annual percentage change was 2.3 per cent. This contrasts with the second highest gap in $2009(-2.4$ per cent). The annual percentage change in GDP was -2.7 per cent whereas annual percentage change for the potential GDP was 1.2 per cent. The -2.7 per cent can be attributed to the economic downturn beginning in 2008 reaching its lowest point in 2009. The negative trend (the difference between actual and potential GDP rates) continued in 2010, 2011 and 2012. In 2013 the estimated gap is positive, estimated at 0.4 per cent of potential GDP.

If we compare these estimates to the ones related to other Mediterranean Member States, some interesting contrasts emerge. Take Italy and Cyprus, for instance. The estimated gap for Cyprus in 2013 is -2.0 per cent which is a reflection of the financial and economic crisis plaguing Cyprus at present. As expected, negative gaps emerge between 2009 and 2012 with the widest gap occuring in 2013. In the case of Italy the widest gap took place in 2009 with negative gaps continuing in the following years. The estimated gap in 2013 remains high at -2.3 per cent.

As for Greece, the estimated potential gap was widest in 2012 at -10.7 per cent with the gap estimated at -9.0 per cent in 2013. These figures are the highest among the selected countries with Spain reaching -3.6 per cent, and France with -2.7 per cent in 2013. Greece, Spain, Italy, France and Cyprus are clearly still facing economic crisis with the prospects for Greece and Spain, in particular, remaining bleak. As shown above, the estimated gap between actual and potential GDP is positive in the case of Malta in spite of the economic recession that hit Malta in 2008. The economy has shown signs of resilience and is slowly emerging from the slow growth rates that have characterised the immediate years following the recession. Compared with Greece, Spain and Italy, in particular, there are much fewer idle resources in Malta though it is not surprising that the rate of inflation is somewhat higher in the Maltese economy.

In July 2012 the inflation rate for the Maltese economy reached 4.2 per cent. This was the highest inflation rate in all Eurozone Member States, and the second highest inflation rate across the EU. Significantly lower inflation rates were registered in Greece and other Mediterranean Eurozone Member States providing further evidence that economic slowdown was accompanied by a slowing down of inflation. Malta's inflation rate has remained among the highest in the Eurozone but measured 3.3 per cent in February 2013. 
The common factor across the selected Member States is that they are all part of the Eurozone, and any difference between actual and potential GDP may require monetary stimulus. However, the varying levels of gaps between actual and potential GDP indicate that economies in the Member States selected require somewhat different responses in order to close the gap. This explains why the Eurozone has struggled to find optimal solutions to the huge debt and deficit problems faced by Greece and Spain in particular. The sizeable gap between actual and potential GDP clearly warrants fiscal adjustment which makes economic growth prospects and hence any attempt at closing the gap more difficult to achieve. In the meantime, the amount of potential output lost by the Greek and Spanish economies has translated into fewer jobs being available to willing workers. Also, the productivity of workers who are unemployed is irrevocably lost to the economies. This shows that for Eurozone members such as Greece and Spain, monetary stimulus alone is not the answer to closing the gap between actual and potential GDP.

\section{Cyclical Components of Public Revenues and Expenditures}

In this section, the cyclical components of public revenues and expenditure of the selected Member States are compared. The objective is to determine whether the cyclical component of revenues is higher than the cyclical component of expenditure. The actual, structural and cyclical deficit will also be considered.

It should be noted that the estimates of the cyclical component of budget aggregates are based on the responsiveness of actual revenue and expenditure to deviations from the potential level of output. On the other hand, the cyclical component of revenues are based on elasticties of marginal and average tax rates for personal, corporate, indirect and social security contributions.

From a budgetary perspective, and assuming that the economy has grown above its potential and the actual deficit is lower than the structural deficit, there is a risk that policy makers implement expansionary policies by increasing expenditure through cyclical-based income. Added to this is the impact of pro-cyclical discretionary policy which has diluted the role of automatic stabilizers in stabilising the economic cycle.

The cyclical component of total revenues as a percentage of GDP for the Maltese Islands is negative for $1995(-0.2$ per cent), 2004 to 2007 (-1.0,-0.7, -0.6, -0.2 per cent), and between 2009 and 2012 (-0.8, -0.5, -0.1, - 0.1 per cent). In 2013 , it is 0.1 per cent of GDP. Insofar as total expenditure is concerned, the cyclical component as a percentage of GDP is 0.0 per cent in all years (1995 and between 2000 and 2013). However, the net borrowing (actual balance) as a percentage of GDP is negative for all years with the highest level reached in 2003 (-9.2 per cent). The levels between 2008 and 2013 except for 2008 (-4.6 per cent) are not extraordinarily high especially when compared with Greece, Spain and France. The cyclical component of net lending or borrowing as a percentage of GDP for the Maltese economy is comparable with levels in the other countries selected apart from Greece. The difference between the cyclical component of revenue and the cyclical component of expenditure is positive in 2013 for the Maltese economy unlike the other Member States selected with Greece showing a negative 3.7 per cent of GDP.

It is clear that in the case of Greece and to a lesser extent for all Member States selected, (and somewhat a lesser extent in the case of Malta) the cyclical deficits are the result of lower revenues and higher expenditures on social programmes such as unemployment benefits. It is pertinent to note that Malta has a significantly lower level of unemployment compared with the other selected Member States. The highest rates in the Euro zone were recorded in Greece (26.4 \% in December 2012), Spain (26.3\%) and Portugal (17.5 \%) but the unemployment rate has also increased in Cyprus and Italy. With lower levels of unemployment in Malta, this implies lower spending levels on unemployment benefits and hence a lesser effect on cyclical deficits compared to Greece and Spain especially.

\section{Adopting the Fiscal Compact (Focusing on Malta)}

Against this background of cyclical deficits, the so-called Fiscal Compact shall impose a very strict regime over government finance, and this would have implications insofar as the application of discretionary fiscal policy is concerned. It would be relevant at this point to refer to the most recent budget deficit figures between 2005 and 2011. In 2005, 2006 and 2007, the figures were $-2.9,-2.8$ and -2.4 per cent respectively, rising to -4.6 per cent in 2008; remaining at abnormally high levels in 2009 and 2010, and going down to -2.7 per cent in 2011.

Assuming the fiscal compact had been in place between 2005 and 2011, the cyclically adjusted deficit in excess of the requirement of 0.5 per cent structural deficit would have been $-1.8,-1.7,-1.7,-4.6,-2.4,-2.7,-2.1$ and -2.0 per cent. It should be noted that a limit on the structural deficit means that a country can run a deficit above the limit to the extent and only to the extent - that the gap between revenue and spending is cyclical (that is, its economy is operating below potential due to temporary negative shocks). In other words, the target is cyclically adjusted. 
In Malta's case, it is evident that the cause for the budget's deficit has been mainly due to factors other than cyclical such as accelerating intermediate consumption, higher social transfers and the rise in compensation of employees in the public sector. In view of this, the structural budget deficit may constrain the ability of government to sustain its present revenue and expenditure policies. An understanding of the structural component of the fiscal position as opposed to its cyclical element is important for sustainable long-term government financing and planning. In fact, the main causes of the structural deficit are the ever-increasing expenditures on health, social welfare (especially pensions expenditure), and spending on education and other recurrent expenditures.

Also significant is that the structural deficit reflects a fundamental, long-term or underlying imbalance between government receipts and expenditure - as opposed to a budget deficit that results from short-term factors that are related to the business-cycle. Moreover, a structural deficit differs from a cyclical deficit in that the former is present even when the economy is growing at its potential: when there is no recession or cyclical downturn. Given that spending on health, welfare and education are rising, government's structural deficit is more chronic or long-term in nature than its cyclical deficit. In fact, the structural deficit can be defined as the intended outcome of government policies on health, welfare and education, and therefore can only be reduced by explicit and direct government policy changes, such as reducing expenditure and/or increasing tax rates.

It is evident that in adopting the Fiscal Compact Malta will need to address the structural nature of its budget deficit. This will no doubt present serious challenges to the government, but one needs to balance this with the advantage of adopting the Fiscal Compact particularly in view of the very low risk of pro-cyclical fiscal policies. If, for example, the Maltese economy was growing above its potential in a particular year, an actual budget deficit in a particular year would, under the Fiscal Compact rule, be changed into a budget surplus. The disadvantage is the fact that government will be allowed to reduced fiscal elbow room during recessions. The ability of government to contribute to the smoothing of fluctuations in the business cycle will largely depend on whether automatic stabilizers can accommodate the cycle. Put differently, Malta may need a stronger discretionary fiscal stimulus or a structural deficit when faced with a recession.

Against this background, it may be relevant to assess at what stage in the case of Malta the structural deficit of 0.5 per cent of GDP will be reached as compared with the 3 per cent of GDP for actual government deficit. If we accept the forecasts by the European Commission in its European Economic Forecast (Spring, 2013), the deficit is expected to widen to 3.7 per cent of GDP in 2013 meaning that the structural deficit target will not be reached for the foreseeable future. Assuming there are no policy shifts, the main causes of Malta's structural deficit will persist with the structural budget balance forecast remaining relatively high in 2013 and 2014 at -3.8 and -3.7 per cent respectively. It should also be noted that in 2013 measures were introduced to reduce the income tax rates for most income earners. As a consequence of this, a marginal fall in current revenues is projected for both 2013 and 2014.

It has now been determined that, on average, over an economic cycle, the effective budget deficit should be 0.5 per cent of GDP. In the light of this, it may be relevant to compare the public debt of the selected states and determine the GDP per capita as a percentage of the EU 27 average (now 28). Equally, it may be useful to compare forecasts for public debt (as a percentage of GDP) in the selected countries. The fiscal compact requirement of 0.5 per cent of GDP ceiling for the structural deficit is expected to result in a lower public debt as a percentage of GDP in the medium to long term. In Malta's case, the debt-to-GDP ratio is projected to continue to rise in 2013 and 2014 to 73.9 and 74.0 per cent respectively. This is due to the increase in the primary deficit. Compared with Greece (175.2 and 175.0 per cent in 2013 and 2014), Spain (91.3 and 96.8 per cent in 2013 and 2014), Italy (131.4 and 132.2 per cent in 2013 and 2014), France (94.0 and 96.2 per cent in 2013 and 2014) and Cyprus (109.5 and 124.0 per cent in 2013 and 2014), Malta's debt-to-GDP ratio is not as high. One should note, however, that if the obligations by the state-owned energy company, Enemalta, were included in the debt calculation, Malta's debt-to-GDP ratio would rise to 90 per cent (New York Times, 2013). Malta has used government guarantees as a way of loading up on debt without having it shown up in the government debt figure. However, if the financial status of Enemalta were to deteriorate further, the government would be required to absorb these debts, and thereby leading to a hike in general government debt.

In Malta's case and as stated previously, reducing debt will require policy shifts particularly in the health, education, and pensions. Just as important, Malta needs to double its efforts to absorb the EU funds over the adjustment period. The EU funds absorption is an important stimulus for the economy especially in the context of discretionary fiscal policy restrictions resulting from the new fiscal compact and the small size of automatic stabilizers.

Related to this there is the necessity to increase efficiency in public spending. This requires first and foremost, linking spending to national priorities (as it has been determined in the National Strategic Reference Framework in the case of Malta), and ensuring that recurrent spending derives the best value for money. In practical terms, this means that the financial resources allocated for public investment expenditure should result in monetary as well as in non-monetary benefits for residents and non-residents alike. If, despite the public investment expenditure, the return to citizens remains 
poor, then this will be a critical problem for Malta and its quest to enhance the efficiency in public spending.

In this connection it may be pertinent to highlight the findings of a study by the European Commission that concluded that public healthcare expenditure efficiency in Malta is weak, and that of tertiary education expenditure is below the EU average. The report, which is entitled The Efficiency of Public Expenditure in Malta, exclusively focuses on public spending in education and healthcare, which together represent around 30 per cent of total government expenditure in Malta.

The findings show that, whereas public expenditure in Malta appears relatively efficient at the primary and secondary levels of (schooling) education, this is not the case at the tertiary/further level. These results seem to be confirmed when efficiency is assessed from the output side. It is argued that cultural impediments, for instance those hampering female participation in tertiary/further education, may partly explain the outcome.

Similarly, the extent to which the cost incurred by the government in giving maintenance grants leads to further increased participation in tertiary/further education is considered to be tenuous. Concerning health, the results show that, even in the context of poor outcomes for the other member states, the efficiency of public healthcare expenditure in Malta is weak. Although the results are indicative and should therefore be interpreted with caution, the findings suggest that there is scope for rationalising tertiary/further education and healthcare spending without compromising the outcomes. In these areas, Malta appears to perform inefficiently, due to high spending rather than to weak outcomes. It is therefore crucial to identify the institutional and structural factors that prevent Malta from achieving higher public spending efficiency in these areas.

\section{Conclusions}

Against this background, the new fiscal compact can have advantages for the Malta economy, with the introduction of a strict fiscal discipline, thus avoiding the pro-cyclicality of discretionary fiscal policy. This, however, could also have some negative effects, since the use of discretionary fiscal policy, especially in times of recession, would be limited if at all possible, whereas the automatic stabilizers would be relatively ineffective in stabilizing the economy.

We also have to take into consideration the likelihood that the 0.5 per cent of GDP structural deficit will be far more restrictive for Malta than the 3 per cent of GDP ceiling for actual deficit. This will require the Maltese authorities to (a) further increase the absorption rate for EU funds (though it must be said that Malta has a relatively high rate of absorption already) (b) increase efficiency of public spending by focusing expenditure in those services which maximise the return to the citizens and based on a redistributive justice, and (c) increase the magnitude of automatic stabilizers.

Overall, the 0.5 per cent of GDP ceiling for structural deficit is likely to result in a substantial reduction of the public debt (as a percentage of the GDP) in the medium and long term. For a small economy like Malta that is still heavily dependent on public spending (both recurrent and capital) as a major source of income for individuals, households and businesses, this may not all be positive. It may even result in a slippage on Malta's public finance commitments. One thing is for certain, however. Fiscal consolidation cannot be avoided and as the European Commission itself has concluded Malta's structural imbalances requiring both monitoring and policy action. Malta's high corporate and government debt levels cannot remain at current levels to ensure the long-term sustainability of public finances.

\section{References}

Bordo D Michael, Markiewicz Angieszka, and Jonung Lars (NBER Working Paper No.17380, 2011).

Ebejer Ivan and Mandl Ulrike, The Efficiency of Public Expenditure in Malta (Country Focus Volume 6, Issue 2, February 2009, European Commission).

European Commission, Cyclical Adjustment of Budget Balances (Spring 2012 and 2013).

European Commission, European Economic Forecast (Spring 2013).

Eurostat, Overview of Competitiveness in 27 Member States (Memo/11/702, October 2011).

The New York Times (Global Business), State Debt Guarantees That are 'Hidden' Add Worries in Europe (February 6, 2013). 